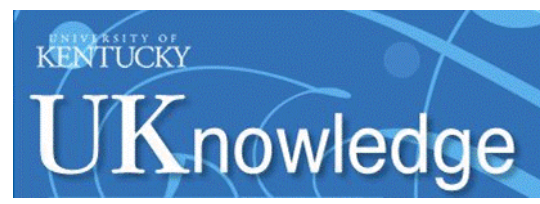

University of Kentucky

UKnowledge

$11-2015$

\title{
General Education Program in a New 4-Year University Curriculum in Hong Kong: Findings Based on Multiple Evaluation Strategies
}

\author{
Daniel T. L. Shek \\ University of Kentucky \\ Lu Yu \\ The Hong Kong Polytechnic University, China \\ Florence K. Y. Wu \\ The Chinese University of Hong Kong, China
}

Follow this and additional works at: https://uknowledge.uky.edu/pediatrics_facpub

Part of the Pediatrics Commons

Right click to open a feedback form in a new tab to let us know how this document benefits you.

\section{Repository Citation}

Shek, Daniel T. L.; Yu, Lu; and Wu, Florence K. Y., "General Education Program in a New 4-Year University Curriculum in Hong Kong: Findings Based on Multiple Evaluation Strategies" (2015). Pediatrics Faculty Publications. 197.

https://uknowledge.uky.edu/pediatrics_facpub/197

This Article is brought to you for free and open access by the Pediatrics at UKnowledge. It has been accepted for inclusion in Pediatrics Faculty Publications by an authorized administrator of UKnowledge. For more information, please contact UKnowledge@lsv.uky.edu. 
General Education Program in a New 4-Year University Curriculum in Hong Kong: Findings Based on Multiple Evaluation Strategies

Digital Object Identifier (DOI)

https://doi.org/10.1515/ijdhd-2015-0459

Notes/Citation Information

Published in International Journal on Disability and Human Development, v. 14, no. 4, p. 377-384.

(c) 2015 Walter de Gruyter GmbH, Berlin/Boston

The copyright holders have granted the permission for posting the article here. 


\section{Daniel T.L. Shek*, Lu Yu, Florence K.Y. Wu and Catalina S.M. Ng General education program in a new 4-year university curriculum in Hong Kong: findings based on multiple evaluation strategies}

DOI 10.1515/ijdhd-2015-0459

Received June 20, 2014; accepted August 18, 2014; previously published online September 17, 2015

\begin{abstract}
Since the 2012-2013 academic year, undergraduate programs in Hong Kong have been changed from 3 years to 4 years, with the additional year focusing primarily on general education. A new general education framework entitled General University Requirements (GUR) implemented at The Hong Kong Polytechnic University (PolyU) was examined in a 5-year longitudinal project. Based on different evaluation strategies, including objective outcome evaluation, subjective outcome evaluation and qualitative evaluation (focus groups, case studies, and document analyses), findings consistently showed that students had positive perceptions of the subject content, teachers as well as teaching and learning methods in GUR subjects. A large majority of students perceived that the GUR subjects were effective in promoting the five desirable graduate attributes defined by PolyU (i.e. problem solving, critical thinking ability, effective communication, ethical leadership, and lifelong learning).
\end{abstract}

Keywords: Chinese adolescents; general education; university students.

\footnotetext{
*Corresponding author: Professor Daniel T.L. Shek, PhD, FHKPS, SBS, JP, Associate Vice President and Chair Professor, Faculty of Health and Social Sciences, Department of Applied Social Sciences, The Hong Kong Polytechnic University, Room HJ407, Hunghom, Hong Kong, P.R. China, E-mail: daniel.shek@polyu.edu.hk; Centre for Innovative Programs for Adolescents and Families, The Hong Kong Polytechnic University, Hong Kong, P.R. China; Department of Social Work, East China Normal University, Shanghai, P.R. China; Kiang Wu Nursing College of Macau, Macau, P.R. China; and Division of Adolescent Medicine, Department of Pediatrics, Kentucky Children's Hospital, University of Kentucky College of Medicine, Lexington, KY, USA

Lu Yu, Florence K.Y. Wu and Catalina S.M. Ng: Faculty of Health and Social Sciences, Department of Applied Social Sciences, The Hong Kong Polytechnic University, Hunghom, Hong Kong, P.R. China
}

\section{Introduction}

The Hong Kong higher education system has experienced an unprecedented change since 2012 when all the universities funded by the University Grants Committee had to extend the length of their undergraduate degree programs from 3 to 4 years. This 'significant and monumental change' [1, p. 193] has brought about the inclusion of general education (GE) into the curriculum which has become a mandatory requirement for all undergraduate students in Hong Kong. Consistent with this new policy, The Hong Kong Polytechnic University (PolyU), which is one of the eight public universities in Hong Kong, has developed a new general education framework entitled the General University Requirements (GUR). To evaluate the effectiveness of the GUR, a 5-year longitudinal project has been conducted starting from the introduction of the new 4-year undergraduate curriculum in the 2012-2013 academic year.

The former President of the University of San Francisco, Reverend Stephen Privett, raised several questions for university educators to ponder. The first question was what the goals of undergraduate education in a globalized world should be. Privett also asked what kind of knowledge, sets of skills, and sensitivity university students should acquire and develop for their undergraduate education. In response to these questions, Aloi et al. [2] argued that 'it is not sufficient for colleges and universities to train students for mere technical competence' (p. 237) in this era of global competitiveness. Allen [3] raised a similar question when he said that 'the new world economy is supposed to be one of flux and endless change. For how long will today's specific technical skills be relevant?' (p. 3), suggesting that solely imparting professional and technical knowledge to university students can no longer best equip them to be able to adapt to in our fast changing and competitive environment. Aloi et al. [2] stressed that 'what is required for graduates' professional and personal success is additional attention to the development of knowledge, skills, and attitudes that will support them throughout their lives' (p. 237). Laird et al. [4] similarly 
elaborated that in the 21st century, university graduates not only must possess a good foundation of knowledge in their own discipline, but they also have to master a wide array of skills such as language and communication skills, quantitative and analytical skills, planning and investigative skills, critical thinking, and problem-solving skills. General education has, therefore, been identified as an important component of the curricula to help students develop those generic skills [5].

In a report entitled 'College learning for the new global century' by the Association of American Colleges and Universities [6], the emphasis was put on the importance of GE in helping students to achieve several essential learning outcomes, such as helping students acquire knowledge, communication skills, problem solving, critical and creative thinking, lifelong learning, and social responsibility. Along the same line, as stated in a report about the employers' views on graduates [7], employers criticized colleges and universities for providing an education which is 'disconnected from the real world' and 'delayed reality' (p. 25). They stressed that colleges and universities should 'address all the broad areas of knowledge, skill, and responsibility that are central to a strong liberal education' (p. 27). Clearly, implementing general education in the higher education sector becomes fundamentally important. The literature reveals that an increasing number of universities worldwide have incorporated GE into their undergraduate curriculum as a pivotal strategy to enhance their students' international competitiveness in a fast-changing world [8].

In order to achieve the aims of undergraduate education, PolyU has developed a new general education framework entitled the General University Requirements, which cultivates five desirable graduate attributes (i.e. critical thinking, effective communication, problem solving, lifelong learning, and ethical leadership). The GUR part of the curriculum includes six major components [9]: Freshman seminar (FS) (3 credits), language and communication requirements (LCR) (9 credits), cluster area requirements (CAR) (12 credits), leadership and intra-personal development (LIPD) (3 credits), service learning (SL) (3 credits), and healthy lifestyle (0 credit). A total of 107 GUR subjects were offered to all first-year undergraduate students in the 2012-2013 academic year.

Regarding the teaching and learning methods of the GE curriculum, most GUR subjects have adopted interactive and experiential learning approaches. Group projects, hands-on workshops, and field work are included in the subjects with the aim of enhancing students' learning interest and maximizing students' learning outcomes.

\section{Evaluation of GUR at PolyU}

A 5-year longitudinal mixed method design was adopted to evaluate the implementation and effectiveness of GUR subjects. Using the principle of triangulation, various evaluation strategies have been used. Specifically, quantitative methods included online surveys addressing student-level developmental indicators and the Collegiate Learning Assessment (CLA+) were used. Regarding subjective outcome evaluation, standard Students' Feedback Questionnaire (SFQ) on GUR subjects were used. Qualitative evaluation using student focus groups, teacher focus groups, document analysis, and longitudinal case studies was also carried out. A brief overview of different evaluation strategies and the related evaluation findings from the first-year implementation are presented in the sections below.

\section{Objective outcome evaluation (online survey)}

The first objective outcome evaluation strategy is an online survey in which different measures are included: Chinese Interpersonal Reactivity Index (C-IRI), Index of Learning Styles (ILS), Chinese Positive Youth Development Scale (CPYDS), and National Survey of Student Engagement (NSSE). In the first year of assessment, objective outcome evaluation data were collected from 543 students (219 males and 324 females) to measure the five desired graduate attributes (critical thinking, effective communication, problem solving, lifelong learning, and ethical leadership). A brief description of the instruments is outlined as follows:

- Adapted by Siu and Shek [10] based on Davis’s [11] work, the C-IRI was designed to assess empathy in Chinese people. There are 22 items in this scale, including measures of personal distress ( 7 items), fantasy (4 items) and empathy (11 items), measured on a 4-point Likert scale. Student score on this inventory is used as an indicator to reflect one's competence of being an ethical leader and motivation to contribute to the community.

- Another instrument used in the online survey is the ILS. It is a 44-item inventory [12] assessing students' individual learning preferences in terms of remembering, processing information, and solving learning tasks. In this model, the learning styles of an individual can be categorized into four dimensions: active vs. reflective, sensing vs. intuitive, verbal vs. visual, and global vs. sequential [13]. The ILS scales 
are dichotomous with mutually exclusive answers on each item. The ILS was used to reflect students' problem-solving ability.

- The Chinese Positive Youth Development Scale developed by Shek et al. [14] was used to measure positive youth development attributes in Chinese adolescents. A selection of 13 major subscales from the CPYDS with reference to PolyU-desired graduate attributes were adopted for the objective outcome evaluation of GUR, including cognitive competence, emotional competence, behavioral competence, problem solving, social competence, critical thinking, selfleadership, self-determination, self-esteem, ethical leadership, resilience, life-satisfaction, and lifelong learning. Using a 6-point Likert scale, scores in each domain were expressed in terms of average domain items scores. The indexes of CPYDS are used to reflect the students' capacities in problem solving, critical thinking, lifelong learning, ethical leadership, and effective communication as well as other important developmental qualities.

- Another instrument used is the NSSE which evaluates students' university experiences in five major domains: Active and Collaborative Learning; Level of Academic Challenge; Student-Faculty Interaction; Supporting Campus Environment; and Enriching Educational Experience. Responses to the adapted NSSE were measured with a 4-point Likert scale. Composite scores for each NSSE domain were expressed in terms of average domain items scores. Table 1 summarizes the scales used for the objective outcome evaluation.

The data collected from 543 students in the first year have established a descriptive profile of student development at baseline with the scores of different subscales of the C-IRI, CPYDS, ILS, and NSSE and helped identify any changes in students' profile related to the GUR over the next three years. Further publications will be generated from the project utilizing the data collected over time.

\section{Objective outcome evaluation (Collegiate Learning Assessment)}

Another objective outcome evaluation strategy used in the GUR project is the Collegiate Learning Assessment (CLA+) which is a scenario-based, computerized assessment of students' critical thinking, analytic reasoning, problem solving, and written communication skills with reference to real world issues and problems [19, 20]. Data were collected from a sample of 150 Year 1 students and 150 Year
2 students in the 2013-14 academic year. The first round of CLA+ implementation was smooth and successful. The smooth implementation of CLA+ was likely due to the collaboration of the project team, supportive PolyU bodies, including the Department of Applied Social Sciences (APSS), Educational Development Centre, Information Technology Services Office, Office of General University Requirements, and the student helpers. Preliminary findings showed that Year 2 students performed better than did Year 1 students in some domains as well as the overall score.

\section{Subjective outcome evaluation (Students' Feedback Questionnaire)}

To evaluate their perceptions of GUR subjects and the quality of teaching, students were invited to respond to a SFQ at the end of each semester. In the first year, a total of 15,810 questionnaires from 747 classes offering GUR subjects were received, with an average response rate of $75 \%$. The SFQ consisted of 12 closed-response type questions evaluating six major dimensions (i.e. learning outcome; interaction; individual help; organization and presentation; motivation; and feedback) of the teaching and learning experience of university subjects [21, p. 184]. The questionnaire comprised two major parts: Part I focused on the students' learning experience in terms of students' evaluation of the subject, and Part II examined the student perceptions of the staff's teaching. It should be noted that the six common SFQ items are comparable among different GUR components, including four items related to the learning experience in Part I, and two items related to the teaching in Part II, which together form the basis of the current SFQ analysis. Results showed that all ratings were above 3.90 out of a maximum of 5 , indicating a general satisfaction of students with GUR subjects. The participants agreed that they had a clear understanding of the intended learning outcomes (ILO) of the GUR subjects being evaluated $(M=3.98, \mathrm{SD}=0.35)$. They also perceived that the learning activities $(M=3.97, \mathrm{SD}=0.35)$ and assessments $(M=4.00, \mathrm{SD}=0.31)$ helped them achieve the learning outcomes and demonstrate what they had learned in the subject. The assessment criteria were also well understood $(M=3.90, \mathrm{SD}=0.35)$.

Regarding the teaching performance of the staff, the results were even more positive with the mean scores for both items being above 4.0, suggesting that students had positive perceptions of GUR subjects in terms of both the effectiveness of teaching and the learning experience. Results based on analyses of variance showed that SFQ 
Table 1: A summary of the scales for objective outcome evaluation (online survey).

\begin{tabular}{|c|c|c|}
\hline Instruments & Instrument description & Desired attributes \\
\hline $\begin{array}{l}\text { Chinese Positive Youth } \\
\text { Development Scale } \\
\text { (CPYDS) }\end{array}$ & $\begin{array}{l}\text { - A total of } 13 \text { major subscales from the CPYDS pertaining to the PolyU- } \\
\text { desired graduate attributes were adopted for the objective outcome } \\
\text { evaluation of GUR, including cognitive competence, emotional } \\
\text { competence, behavioral competence, problem solving, social competence, } \\
\text { critical thinking, self-leadership, self-determination, self-esteem, ethical } \\
\text { leadership, resilience, life satisfaction, and lifelong learning. } \\
\text { - Using a 6-point Likert scale, scores of each domain were expressed in } \\
\text { terms of average domain items scores. }\end{array}$ & $\begin{array}{l}\text { Problem solving, critical } \\
\text { thinking, lifelong learning, } \\
\text { ethical leadership, effective } \\
\text { communication }\end{array}$ \\
\hline $\begin{array}{l}\text { Chinese Interpersonal } \\
\text { Reactivity Index (C-IRI) }\end{array}$ & $\begin{array}{l}\text { - The Chinese Interpersonal Reactivity Index (C-IRI) is a self-reported } \\
\text { questionnaire designed to assess empathy in Chinese population adapted } \\
\text { by Siu and Shek [10] based on Davis's [11] work. } \\
\text { - The C-IRI comprises } 22 \text { items of personal distress ( } 6 \text { items), fantasy (10 } \\
\text { items) and empathy ( } 6 \text { items), measuring on a 4-point Likert scale. } \\
\text { - As ethical leadership requires the ability of ethical reasoning and empathy } \\
\text { in professional and daily contexts, student score on this inventory is used } \\
\text { as an indicator to reflect one's competence of being an ethical leader and } \\
\text { motivation to contribute to the community. }\end{array}$ & Ethical leadership \\
\hline $\begin{array}{l}\text { Index of Learning Style } \\
\text { (ILS) }\end{array}$ & $\begin{array}{l}\text { - ILS is a widely used 44-item inventory [12] for assessing students' } \\
\text { individual learning preferences in terms of remembering, processing } \\
\text { information, and solving learning tasks. } \\
\text { - In this model, the learning styles of an individual can be categorized into } \\
\text { four dimensions: active vs. reflective, sensing vs. intuitive, verbal vs. } \\
\text { visual, and global vs. sequential [13]. The ILS scales are dichotomous, with } \\
\text { mutually exclusive answers on each item, i.e. either (a) or (b). Responses } \\
\text { to ILS items of the Active, Sensing, Visual, and Sequential scales were } \\
\text { scored by assigning a value of } 1 \text { to (a) options, and } 0 \text { to (b) options. Scores } \\
\text { of the opposite polarities: Reflective, Intuitive, Verbal and Global, can be } \\
\text { found as a complement of } 11 \text { (i.e. if the average Active score is } 6.7 \text {, the } \\
\text { average Reflective score is } 4.3 \text { ). By comparing the scores of respective } \\
\text { opposite polarities, individuals can be categorized into different groups. }\end{array}$ & Problem solving \\
\hline $\begin{array}{l}\text { National Survey of } \\
\text { Student Engagement } \\
\text { (NSSE) }\end{array}$ & $\begin{array}{l}\text { - Students' engagement in learning and other university experience were } \\
\text { assessed with a locally adapted version of the National Survey of Student } \\
\text { Engagement (NSSE) [15]. } \\
\text { - The NSSE has been administered and validated in both the United States } \\
\text { [16] and mainland China }[17,18] \text { with good psychometric properties. The } \\
\text { NSSE evaluates students' university experiences in terms of five major } \\
\text { domains: Active and Collaborative Learning; Level of Academic Challenge; } \\
\text { Student-Faculty Interaction; Supporting Campus Environment; and } \\
\text { Enriching Educational Experience. } \\
\text { - Responses to the adapted NSSE were measured with a 4-point Likert } \\
\text { scale. Composite scores for each NSSE domain were expressed in terms of } \\
\text { average domain items scores. }\end{array}$ & $\begin{array}{l}\text { Lifelong learning, effective } \\
\text { communication }\end{array}$ \\
\hline
\end{tabular}

ratings differed significantly in all six common SFQ items across GUR components. Several observations are highlighted from the results. First, the ratings of FS appeared to be lower than other GUR components on all six items. Second, student ratings of SL were the highest for five out of six items. Third, the subjective evaluation of the teaching staff for LCR and LIPD seemed to be better than other GUR components. Fourth, the mean scores of the six items for all GUR components were above 3.40, suggesting that students generally held positive perceptions of GUR subjects.

The subjective outcome evaluation based on the results of the SFQ provides a way to find out more about students' opinions and subjective experiences of the GUR subjects. Before the effects of the GUR on objective indicators can be consolidated, the subjective outcome evaluation offers immediate and important evidence about the implementation of the curriculum, contributing to the improvement of 
GUR subjects. The current findings of SFQ ratings for GUR subjects in the 2012-2013 academic year are encouraging as students reported favorable views on both the subjects and teachers. The majority of students gave positive comments on the contents of GUR subjects and they found that the intended learning objectives were clear.

Favorable views were also observed in the students' ratings of teachers. The teachers of GUR subjects were perceived as effective in providing students with valuable learning experiences by giving them care and support. This is in line with the literature in the field as it was found that caring teachers increase the level of student engagement in schools [22] and teachers' support is linked to better student achievements [23]. Students had a positive perception of teachers and the teaching and learning approaches.

The interactive teaching and learning methods adopted for the GE subjects were group project or presentation, hands-on activities, and sharing of personal experience. The interactive teaching and learning methods enhanced students' interest and motivation to learn as they found the lessons more enjoyable and stimulating. Existing research showed that using interactive teaching methods is beneficial to students. Students in classes exposed to interactive teaching approaches showed a notable improvement in learning compared with students who were only exposed to the traditional lecture approach [24]. Similarly, students in classes using the interactive teaching and learning approach showed more interest and enjoyment in learning, more satisfaction with the course, and admitted that they had learnt something when compared to students in classes using didactic teaching [25]. The findings indicated that the adoption of interactive teaching and learning approaches for teaching GE is the most beneficial approach, all the more so as the results showed that the interactive teaching and learning method enabled students to learn and develop the desired graduate attributes defined by PolyU. Overall, GUR was generally well received by students in its first year of implementation.

\section{Qualitative evaluation (student focus groups)}

To evaluate the implementation, effectiveness, and challenges of the GUR in its first-year implementation, 62 Year 1 students from eight faculties/schools of PolyU were interviewed in 13 focus groups. Students were asked about the general impression, subject content, teaching and learning, implementation, benefits, and concerns of the GUR. The findings showed that students had positive perceptions of the GUR in terms of subject content, interactive teaching and learning methods, and the effectiveness of GUR subjects. Specifically, students perceived subject contents as very inspiring and well designed. They liked the GUR subjects as they were more interesting and enjoyable than the subjects of their majors, which was probably due to the interactive teaching and learning method such as group discussion. Students expressed that their learning experience was enjoyable and helped them 'really learn something'. The GUR subjects were effective in facilitating the development of critical thinking ability, communication skills, and intention to lifelong learning. Despite minor concerns over the administration of GUR subjects, the results from student focus groups suggested that the first-year implementation of the GUR at PolyU was generally smooth and successful. More details about the results from the student focus groups have been reported elsewhere [9].

\section{Qualitative evaluation (teacher focus groups)}

Besides capturing the perspective of students, the views of the teachers were also explored. Four focus groups $(n=20$ teachers) were conducted to explore their perceptions and experiences in relation to the GUR. Teachers from different GUR components perceived the GUR as important for the development of students beyond their major studies. They responded that the course delivery of different components of GUR subjects was essentially smooth and effective. The effectiveness of the course delivery of subjects in different GUR components was evidenced by the diversified, innovative and interactive teaching and learning methods and the positive effects of these teaching and learning methods on students' learning and development. Some teachers observed that there were marked improvements in students' critical thinking and problem-solving skills after enrolling in the GUR subjects. They believed that GUR subjects provided students with valuable learning experiences which will serve as a foundation to enable them to grow in the future.

However, there were some challenges in the implementation of GUR subjects. First, some teachers expressed that many students encountered difficulties in the CAR subject registration because students in different departments were required to register CAR subjects in different timeslots and students who were assigned a later timeslot would not find any place for many of their favored CAR subjects. Another challenge was the heavy workload arising from teaching many classes of GUR subjects and marking students' assignments. Teachers expressed that there is a need to increase the manpower to assist in teaching in order to sustain the high-quality teaching. The 
details of the results from teacher focus groups have been included in a forthcoming article.

\section{Qualitative evaluation (document analyses)}

The document analysis was based on official documents related to the GUR curriculum delivery, including administrative reports, strategic plans, and minutes from formal committees related to teaching and learning in the GUR curriculum. Specifically, the analyzed documents included documented discussions leading to the formulation of GUR curriculum, reports on the implementation of GUR curriculum from a series of formal bodies, including the Learning and Teaching Committee, Committee on General University Requirements, Departmental Teaching and Learning Committees, and various senior management workshops. The constructive alignment model [26-28] describing intended learning outcomes, teaching and learning arrangements, and assessment of learning outcomes was adopted for analyzing the GUR implementation issues arising from the documents under review. Reports from documents showing constructive alignments and the subsequent actions taken were featured in this analysis. Misalignment issues were also addressed in the analysis and the analysis served as a reference for the management of the University for informing on possible improvements and advancements of the GUR.

Several observations were highlighted from the document analyses. First, the linkages between the ILO of the overall GUR curriculum and its components have been clearly delineated and strategically emphasized in the documents. The five desired graduate attributes of PolyU graduates were well articulated. Second, active learning strategies adopted in GUR subjects were well received. Students appreciated the interactive teaching and learning strategies adopted in GUR subjects, in particular LIPD subjects. The interactive teaching and learning strategies provided students with a caring and supportive learning environment that enabled them to develop the desired knowledge, skills, and attributes. Third, document analyses indicated that timely action has been taken to address the critical issues that emerged during the GUR implementation. For example, the flexible timetabling of the FS has been implemented to address timetabling clashes of FS with other subjects. A working group was formed to review the FS curriculum, of which students expressed confusion about the intended learning outcomes. Fourth, the workload of assignments for some GUR subjects and the level of difficulty or level of competence required for students to complete GUR assignment were an issue arising when analyzing the documents.

The results from the document analyses further support the claim that the GUR subjects were well designed and intended learning objectives were clearly spelt out. Students again showed that they liked the interactive teaching and learning strategies adopted by GUR subjects. Many educational studies have shown that students who are actively involved in the learning process will learn more than those who are passive recipients of knowledge [29]. Lo [30] found that student learning and satisfaction with the course increased in interactive classroom. Similarly, Sher [31] reported that student-instructor interaction was one of the significant contributors of student learning and satisfaction. Results from the document analyses further shed light on the smooth implementation of the GUR, which may be due to the prompt remedial actions taken by the senior management to deal with issues arising from implementation such as the time clashes of CAR subjects with the faculty's own subjects. With support from senior management, the implementation of the GUR subjects was smooth and successful in the academic year 2012-2013.

\section{Qualitative evaluation (longitudinal case study)}

To better understand the views of students on the GUR in an in-depth manner, a group of teachers were invited to follow the students (the "cases") starting from their freshman year to graduation. The administration of the longitudinal case study would help witness the changes and growth of the students by reflecting upon their learning journeys throughout their university lives.

Initially, 71 cases were recruited from different faculties or schools at PolyU. Purposive sampling was adopted in this longitudinal case study. The participants were students joining the student focus group interviews in the 2012-2013 academic year. At the end of the 2012-2013 academic year, ten teachers from the APSS were invited to follow the student cases. Each teacher was responsible for seven cases (except for one teacher who handled eight cases). Up to now, researchers have reported 42 actively engaged cases $(59.2 \%)$ who maintain regular contacts with the researchers and 10 re-activated cases had one or two meetings with the researchers during the past year. The 19 remaining student cases (26.8\%) have showed no interest in joining the study and did not respond to several rounds of invitations by the researchers. These cases have been deleted from the longitudinal study. 
Throughout the academic year, two individual interviews for each student case were administered at the beginning and at the end of the academic year. A revised interview guide with five concise questions was developed in the 2013-2014 academic year to provide more opportunity for students to share their views on the respective questions. The revised interview guide comprised two major categories: a) students' experiences in GUR in relation to personal growth and the development of six graduate attributes of PolyU (three questions); and b) students' perceptions of the university life (two questions). In addition, informal meetings were arranged between the student participants and teachers throughout the year to provide an opportunity to collect information in a more relaxing environment about the positive or negative experiences and difficulties that students encountered at the university.

Several general observations were made from these cases in the past year. Firstly, most of the teachers developed reciprocal student-teacher relationships of trust, which supported the beneficial role of self-disclosure on students' learning outcomes. Secondly, students acknowledged that taking the GUR subjects had provided them opportunities to understand knowledge beyond their own disciplines. Quite a number of teachers reported that the students were exposed to a teaching style and subjects "they have never seen" or "they seldom have experienced before". Thirdly, as revealed in the student and teacher focus group interviews, one of the common teaching and learning methodologies is the interactive discussion sessions in GUR subjects. The teachers from the longitudinal case study learnt from the student cases that students enjoyed these arrangements as collaborative learning activities provided them with another learning avenue to step out their comfort zone. Through these interactive and collaborative activities, the students realized the importance of social and interpersonal skills such as synthesis skills, problem-solving skills, and effective communication. Fourthly, although the students in the present study acknowledged that the GUR components had provided them new learning experiences and were beneficial to their development, some students felt that there might be a need to strengthen the linkage of the GUR components with their disciplines and profession.

\section{Discussion}

There are unique features of this longitudinal evaluation study. First, this is a pioneer study not only in Hong
Kong, but also in different Chinese contexts. As the scientific literature in this area is scarce, this article constitutes an interesting addition to the literature. Second, in contrast to mono-evaluation strategy adopted in many evaluation studies, multiple evaluation strategies were employed in this study. By adopting this strategy, different aspects of General Education can be closely examined. Third, in line with the views of major evaluation societies, different stakeholders were recruited. In particular, views of both students and teachers were collected which can give a more balanced view on the teaching and learning processes in GUR subjects. Fourth, different types of data were collected including objective and subjective outcome evaluation data as well as quantitative and qualitative data. This approach can help to produce 'profiles' of responses and subjective experiences of different stakeholders at the same time. Fifth, in contrast to the common approach of collecting data at one single point of time, longitudinal data were collected which can permit us to look at changes in the students across time. Sixth, with reference to objective outcome evaluation, validated Chinese measures were used in the study. Finally, several qualitative strategies including focus groups, case study, and document analyses were used.

The existing findings generally suggest that GUR subjects are well received and they contribute to the holistic development of the students. For the objective outcome evaluation based on CLA+, findings showed that secondyear students performed better than did the first-year students in terms of the overall CLA+ scores. For the subjective outcome evaluation findings, SFQ findings are generally positive in terms of the learning experience, achievement of the learning outcomes, and teacher effectiveness. For the qualitative evaluation findings, it was found that the students and teachers appreciated the GUR and they perceived the related subjects could benefit the holistic development of the students.

\section{Conclusion}

In conjunction with other evaluation studies [32-34], the present study suggests that the implementation of the GUR at PolyU is encouraging as it helps nurture the whole personal development of the students.

Acknowledgments: The preparation for this article and the GUR are financially supported by The Hong Kong Polytechnic University. 


\section{References}

1. Jaffee $D$. The general education initiative in Hong Kong: organized contradictions and emerging tensions. High Educ 2011. Available at: https://www.unf.edu/ djaffee/Higher\%20 Education-HK\%20article-final.pdf.

2. Aloi SL, Gardner WS, Lusher AL. A framework for assessing general education outcomes within the majors. J Gen Educ 2003;52:237-52.

3. Allen RC. The employability of university students in the Humanities, Social Sciences, and Education: recent statistical evidence. 1998. Available at: http://economics.ouls.ox.ac. uk/12102/1/dp9815.pdf.

4. Laird TF, Niskodẻ-Dossett AS, Kuh GD. What general education courses contribute to essential learning outcomes. J Gen Educ 2009;58:65-84.

5. Chan FT, Leung S, Cheng S. The challenges and opportunities of sub-degree general education development under the new academic structure. In: Corrigan P, editor. General education and university curriculum reform: an international conference in Hong Kong. Hong Kong: City University of Hong Kong and The Hong Kong America Center, 2012. Available at: http://www6. cityu.edu.hk/edge/conference2012/docs/GE_Conference_ Proceedings.pdf.

6. Association of American Colleges and Universities. College learning for the new global century: a report from the National Leadership Council for Liberal Education and America's Promise. Washington, DC, 2007. Available at: http://www.aacu.org/leap/ documents/GlobalCentury_final.pdf.

7. Association of American Colleges and Universities. The LEAP vision for learning: outcomes, practices, impact, and employers' views. Washington, DC, 2011. Available at: https://www.aacu. org/LEAP/documents/leap_vision_summary.pdf.

8. Xing J, Ng PS, Cheng CY, editors. General education and the development of global citizenship in Hong Kong, Taiwan and Mainland China: not merely icing on the cake. London: Routledge, 2012.

9. Shek DT, Yu L, Wu FK, Chen WY. General university requirements at The Hong Kong Polytechnic University: evaluation findings based on student focus groups. Assess Eval High Educ, 2014. Advance online publication. DOI: 10.1080/02602938.2014.960362. Available at: http://www.tandfonline.com/doi/pdf/10.1080/0260293 8.2014.960362.

10. Siu AM, Shek DT. Validation of the Interpersonal reactivity index in a Chinese context. Res Social Work Prac 2005;15:118-26.

11. Davis MH. A multidimensional approach to individual differences in empathy. JSAS 1980;10:85-104.

12. Litzinger TA, Lee SH, Wise JC, Felder RM. A study of the reliability and validity of Felder-Soloman Index of Learning Styles. Paper presented at the proceedings of the 2005 American Society for Engineering Education annual conference and exposition. Portland, OR, 2005.

13. Felder RM, Silverman LK. Learning and teaching styles in engineering education. Eng Educ 1988;78:674-81.

14. Shek DT, Siu AM, Lee TY. The Chinese Positive Youth Development Scale: a validation study. Res Social Work Pract 2007;17:380-91.
15. Carini RM, Kuh GD, Klein SP. Student engagement and student learning: testing the linkages. Res High Educ 2006;47:1-32.

16. Kuh GD. The national survey of student engagement: conceptual framework and overview of psychometric properties. Bloomington, In: Indiana University Center for Postsecondary Research and Planning, 2001:1-26.

17. Shi JH, Wen W. Tsinghua University Undergraduate Education Survey Report, 2010. Tsinghua J Educ 2012;33:6-16.

18. Wang S. The impact on student learning of student engagement in research universities - Based on "NSSE-China" 2009 data analysis. Tsinghua J Educ 2011;32:24-32.

19. Arum R, Roksa J, Cho E. Improving undergraduate learning: findings and policy recommendations from the SSRC-CLA longitudinal project. New York, NY: Social Science Research Council, 2011.

20. Klein S, Benjamin R, Shavelson R, Bolus R. The collegiate learning assessment: facts and fantasies. Eval Rev 2007;31:415-39.

21. Kwan KP. How fair are student ratings in assessing the teaching performance of University teachers? Assess Eval High Educ 1999;24:181-95.

22. Black $S$. The power of caring to help kids adjust and achieve is now documented. ASBJ 2006;193:46-9.

23. Klem AM, Connell JP. Relationships matter: linking teacher support to student engagement and achievement. J School Health 2004;74:262-73.

24. Deslauriers L, Schelew E, Wieman C. Improved learning in a large-enrollment Physics class. Science 2011;332:862-4.

25. Chang W, Jones A, Kunnemeyer R. Interactive teaching approach in Year one university physics in Taiwan: implementation and evaluation. APFSLT 2002;3:1-23.

26. Biggs J. Enhancing teaching through constructive alignment. High Educ 1996;32:347-64.

27. Biggs, J. The reflective institution: Assuring and enhancing the quality of teaching and learning. High Educ 2001;41:221-38.

28. Kennedy KJ. Conceptualizing quality improvement in higher education: policy, theory and practice for outcomes based learning in Hong Kong. J High Educ Pol Manag 2011;33: 205-18.

29. Steinert $Y$, Snell LS. Interactive lecturing: strategies for increasing participation in large group presentations. Med Teach 1999;21:37-42.

30. Lo CC. Student learning and student satisfaction in an interactive classroom. J Gen Educ 2010;59:238-63.

31. Sher A. Assessing the relationship of student-instructor and student-student interaction to student learning and satisfaction in web-based online learning environment. J Interactive Online Learn 2009;8:102-20.

32. Shek TL, Yu L. Post-course subjective outcome evaluation of a subject on leadership and intrapersonal development for university students in Hong Kong. Int I Disabil Hum Dev 2014;12:193-201.

33. Shek TL, Ma CM. Do university students change after taking a subject on leadership and intrapersonal development? Int J Disabil Hum Dev 2014;13:451-56.

34. Shek DT, Yu L. Post-course subjective outcome evaluation of a subject on leadership and intrapersonal development for university students in Hong Kong. Int J Disabil Hum Dev 2014;13:457-64. 